\title{
Resource utilization of organic spent adsorbent to prepare three-dimensional sulfate-functionalized layered double oxide for superior removal of azo dye
}

\section{Lingjie Zhang}

Nanchang University

\section{Siyin Zheng}

Nanchang University

\section{Peng Li}

The University of Queensland

Zhongbang Zhu

Nanchang University

\section{Youqin Zou}

Nanchang University

Ping Zhang ( $\nabla$ zhangping@ncu.edu.cn )

Nanchang University

\section{Research Article}

Keywords: Organic spent adsorbent, Sulfate-functionalized layered double oxide, Methyl orange, Superior adsorption, Regeneration, Removal mechanism

Posted Date: April 6th, 2021

DOI: https://doi.org/10.21203/rs.3.rs-340259/v1

License: (c) (i) This work is licensed under a Creative Commons Attribution 4.0 International License. Read Full License 
1 Resource utilization of organic spent adsorbent to

2 prepare three-dimensional sulfate-functionalized

3 layered double oxide for superior removal of azo dye

$4 \quad$ Lingjie Zhang ${ }^{1} \cdot$ Siyin Zheng ${ }^{1}$. Peng $\mathrm{Li}^{2} \cdot$ Zhongbang Zhu $^{1} \cdot$ Youqin Zou ${ }^{1} \cdot$ Ping

5 Zhang ${ }^{1, *}$

6

$7 \quad{ }^{1}$ Key Laboratory of Poyang Lake Environment and Resource Utilization, Ministry of

8 Education, School of Resources Environmental and Chemical Engineering, Nanchang

9 University, Nanchang 330031, P. R. China

$10{ }^{2}$ Australian Institute for Bioengineering and Nanotechnology, The University of

11 Queensland, Brisbane, QLD 4072, Australia

$12 *$ Corresponding author:

13 Ping Zhang, Email: zhangping@ncu.edu.cn

14 


\section{Abstract}

Developing superior, rapid, cost-effective adsorbents derived from organic spent adsorbent is an economically sustainable way for purifying azo dye wastewater. Herein, we report a precursor-calcination strategy for the recycle of the organic spent adsorbent to a high value-added three-dimensional sulfate-functionalized MgAl-layered double oxide (3S-LDO). Thanks to the unique property of the sulfate group and LDO, 3S-LDO exhibited a superior $(4340.71 \mathrm{mg} / \mathrm{g}$ ) and ultrafast ( $<1$ hour) adsorption toward methyl orange (MO, as the representative of azo dye). A thermodynamic study revealed that the reaction process was spontaneous and exothermic. FT-IR, XPS, and XRD results confirmed that the sulfate from 3SLDO played a vital role in MO removal wherein the $\mathrm{S}=\mathrm{O}$ bond (with the electrophilic character) from $\mathrm{SO}_{4}{ }^{2-}$ interacted with the $\mathrm{N}=\mathrm{N}$ double bond (with rich electron) in $\mathrm{MO}$ through the electron donor-acceptor mechanism. And the "memory effect" and surface complexation of 3S-LDO further strengthened the MO adsorption. More importantly, 3S-LDO could work efficiently in a wide $\mathrm{pH}$ range and even in the presence of competitive anions (e.g., $\mathrm{Cl}^{-}, \mathrm{NO}_{3}^{-}$, and $\mathrm{CO}_{3}{ }^{2-}$ ). Multiple cyclic runs and selective tests demonstrated the excellent reusability and explicit selectivity of 3S-LDO. This work not only provides a prospective sulfate-functionalized adsorbent from organic waste for rapid azo dye removal from wastewater but also achieves the high value-added utilization of organic waste.

\section{Keywords}

Organic spent adsorbent · Sulfate-functionalized layered double oxide · Methyl orange $\cdot$ Superior adsorption $\cdot$ Regeneration $\cdot$ Removal mechanism 


\section{Introduction}

$$
\text { Excessive discharge of organic dyes has already caused severe risk to the ecological }
$$
system and human health (Ji et al. 2021). Particularly, azo dyes are proven to be more toxic, carcinogenic, and even mutagenic compared to other forms of dyes, which are composed of aromatic rings and covalent azo bonds $(\mathrm{N}=\mathrm{N})$ (Gurav et al. 2021; Kelm et al. 2019; Oon et al. 2020). Over the past few decades, a vast of strategies, such as catalytic (Fu et al. 2019), photocatalytic degradations (Riaz et al. 2020), adsorption (Khaled et al. 2020), membrane (Yang et al. 2020), filtration (Mohtor et al. 2017), have been conducted on the elimination of azo dye from wastewater. However, challenges inherent to azo dye removal still include expensive cost, low-efficiency, poor regeneration, or membrane fouling, hindering their largescale applications. Therefore, it is still an urgent requirement to develop a technique with preeminent ability, rapid kinetic, cost-efficiency, and outstanding reusability for azo dye wastewater treatment.

Layered double hydroxides (LDHs), known as a class of 2:1 type anionic clay minerals, are gaining widespread attention in water purification due to their flexible layered crystal structure, ion-exchange ability, and "memory effect" (Chen et al. 2021; Hu et al. 2020; Li et al. 2020). It is worth mentioning that the "memory effect" is primarily responsible for endowing LDHs applied in organic wastewater treatment. That is, after LDHs effectively capturing organics from the water via ion-exchange and/or surface adsorption, the spent LDHs can be calcined at moderate temperatures to form the layered double oxides (LDOs), which can restructure to LDHs via rehydrate based on the "memory effect". (Kundu and Naskar 2019; Lv et al. 2018; Vu and $\mathrm{Wu} 2020)$. In fact, LDOs have been reported as environmental remediation 
agents for pollutants elimination from the water with superior capacity and reusability. Zhang et al. reported that the rhombic dodecahedral CaAl-LDO obtained by the calcination of spent CaAl-LDH exhibited a high adsorption capacity $(\sim 500 \mathrm{mg} / \mathrm{g})$ for Congo red and high removal efficiency (93\%) after five consecutive cycles (Zhang et al. 2018). Our previous works also found that the hierarchical organic MgAl-LDH (O3D-LDH) possessed excellent reusability after MO adsorption based on the formation of MgAl-LDO in four continuous cycles (Zhang et al. 2019b). LDOs can be served as the high value-added products of organic spent LDHs to resolve the recovery of the LDHs applied in the organic wastewater treatment. In recent, with the deeper concept of resource utilization, researchers have constantly focused on the adsorbed organic compounds with valuable elements such as $\mathrm{C}, \mathrm{S}$ and $\mathrm{N}$, which can be converted into useful functional components (Laipan et al. 2015; Rong et al. 2020; Tang et al. 2017; Wan et al. 2019). Take sulfur as an example, the sulfate group resulted from S recovery can enhance such adsorbents for azo dye, since the electron-withdrawing property of sulfate exhibits a strong affinity toward electron-rich $\mathrm{N}=\mathrm{N}$ bond of azo dye (Feng et al. 2020; Han et al. 2016; Zhao et al. 2011). Inspired by these researches, if the spent LDHs adsorbed sulfur-containing organics are exploited to synthesize a sulfate-dropped functional renewable LDO, it will not only offer a promising capture agent for azo dye but also achieve the resource utilization of organic spent waste.

In our previous works, we had successfully captured sodium dodecyl sulfate (SDS, persistent organic pollutants) with LDH to generate 3D S-containing MgAl-LDH (3S-LDH) (Zhang et al. 2019a). Herein, we attempted to employ 3S-LDH as the precursor to fabricate 3D sulfate-functionalized MgAl-LDO (denoted as 3S-LDO) through calcination examined by X- 
ray diffraction (XRD), the Fourier transform infrared spectroscopy (FT-IR), X-ray photoelectron spectroscopy (XPS), scanning electron microscope (SEM), and transmission electron microscopy (TEM). To investigate the adsorption performance of 3S-LDO toward azo dyes, methyl orange (MO), with two aromatic rings and azo fragment, was selected as a representative target contaminant (Siyasukh et al. 2018). The effect of various experimental conditions (adsorbent dosage, contact time, initial concentration, temperature, and ion strength) was systematically investigated. And the interaction mechanism between MO and 3S-LDO was further revealed via microstructure analysis. Additionally, the reusability, selective performance, and the adsorption ability of 3S-LDO in real waters were investigated as well.

\section{Material and methods}

\section{Materials}

Magnesium nitrate hexahydrates $\left(\mathrm{Mg}\left(\mathrm{NO}_{3}\right)_{2} \cdot 6 \mathrm{H}_{2} \mathrm{O}\right)$, aluminum nitrate nonahydrate $\left(\mathrm{Al}\left(\mathrm{NO}_{3}\right)_{3} \cdot 9 \mathrm{H}_{2} \mathrm{O}\right)$, urea $\left(\mathrm{H}_{2} \mathrm{NCONH}_{2}\right)$, sodium dodecyl sulfate (SDS, $\left.\mathrm{C}_{12} \mathrm{H}_{25} \mathrm{SO}_{4} \mathrm{Na}\right)$, citric acid $\left(\mathrm{CA}, \mathrm{C}_{6} \mathrm{H}_{8} \mathrm{O}_{7}\right)$ and methyl orange $(\mathrm{MO})$ with analytical grade were purchased from Aladdin Chemicals Reagent Company (Shanghai, China). Ltd and used without further purification. Solutions used in the experiments were carried out with deionized water.

The tap water, river water, and industrial wastewater were collected from the laboratory, Jiangxi before the lake, and a factory in Jiujiang, Jiangxi province, respectively. The freshwater samples were previously filtered with qualitative filter paper (Jiao Jie, China) upon arrival and stored at $4{ }^{\circ} \mathrm{C}$ in a refrigerator. 
In general, $\mathrm{Al}\left(\mathrm{NO}_{3}\right)_{3} \cdot 9 \mathrm{H}_{2} \mathrm{O}(0.1500 \mathrm{~g}), \mathrm{Mg}\left(\mathrm{NO}_{3}\right)_{2} \cdot 6 \mathrm{H}_{2} \mathrm{O}(0.2051 \mathrm{~g})$, and urea $(0.2402 \mathrm{~g})$ were dissolved in $50 \mathrm{~mL}$ deionized water. Subsequently, SDS solution $(30 \mathrm{~mL})$ with the initial concentrations of $0.1 \mathrm{M}$ was immediately added into above mixed solution. After vigorously stirring (30 min) and ultrasonication (30 min), the suspension was transferred into a Teflon lining stainless steel autoclave and treated at $150{ }^{\circ} \mathrm{C}$ for $6 \mathrm{~h}$. Finally, the precipitation, i.e., 3S$\mathrm{LDH}$, was collected via centrifugation and dried at $70^{\circ} \mathrm{C}$ for $6 \mathrm{~h}$. To prepare 3S-LDO, 3S-LDH was heated at $700{ }^{\circ} \mathrm{C}$ in a muffle furnace for $4 \mathrm{~h}$. using citric acid instead of SDS (Cao et al. 2019). Then, 3D-LDO was obtained via the calcination of 3D-LDH at $700{ }^{\circ} \mathrm{C}$. The successful synthesis of 3D-LDH and 3D-LDO was confirmed by XRD and FT-IR, and SEM (Fig. S1).

\section{Adsorption experiments} investigated with different $3 \mathrm{~S}-\mathrm{LDO}$ dosages $(0.1,0.3,0.5,0.7,1.0 \mathrm{~g} / \mathrm{L})$. The adsorption isothermal experiments for MO removal by 3S-LDO and 3D-LDO were carried out with the initial MO concentrations of $20-4000 \mathrm{mg} / \mathrm{L}$ at diverse temperatures $\left(25,35\right.$, and $\left.45{ }^{\circ} \mathrm{C}\right)$, respectively. For adsorption kinetic, the experiments were performed at various intervals ( $0-12$ h) with different MO concentrations (10, 1000, and $2000 \mathrm{mg} / \mathrm{L}$ for 3S-LDO; $1000 \mathrm{mg} / \mathrm{L}$ for 3D- 
$\mathrm{Cl}^{-}, \mathrm{NO}_{3}{ }^{-}$, and $\mathrm{CO}_{3}{ }^{2-}$ at various concentrations $(0.02,0.04,0.06,0.08$, and $0.1 \mathrm{M})$. For all tests, a certain quantity of 3S-LDO or 3D-LDO was added to the $10 \mathrm{~mL}$ MO solution. The mixture was shaken at $150 \mathrm{rpm}$ for $12 \mathrm{~h}$ and filtered through a $0.45 \mu \mathrm{m}$ polycarbonate membrane. The residual MO concentrations were analyzed using a UV-vis spectrophotometer (V-1600 spectrophotometer) at a wavelength of $463 \mathrm{~nm}$ (Siyasukh et al. 2018).

The adsorption capability and efficiency were calculated according to the formulas:

$$
\begin{gathered}
q_{\mathrm{e}}=\frac{\left(C_{0}-C_{\mathrm{e}}\right) V}{m} \\
E=\frac{C_{0}-C_{\mathrm{e}}}{C_{0}} \times 100 \%
\end{gathered}
$$

Where $q_{\mathrm{e}}(\mathrm{mg} / \mathrm{g})$ is the adsorption amount of MO per gram of absorbents at equilibrium time. $C_{0}$ and $C_{\mathrm{e}}(\mathrm{mg} / \mathrm{L})$ represent $\mathrm{MO}$ concentrations in supernatants at initial and equilibrium conditions, respectively. $V(\mathrm{~L})$ is the solution volume, $m(\mathrm{~g})$ refers to the mass of the adsorbent. A selective adsorption experiment of dyes was performed by adding $3 \mathrm{mg}$ of 3S-LDO in $10 \mathrm{~mL}$ of dye mixture solution containing $100 \mathrm{mg} / \mathrm{L} \mathrm{MO}$ and $50 \mathrm{mg} / \mathrm{L} \mathrm{MB}$. The equilibrium concentration of the mixture solution was calculated by UV-vis spectra.

\section{Solid preparation}

$0.03 \mathrm{~g}$ 3S-LDO was added to $100 \mathrm{~mL}$ MO solution with concentrations of 20, 1000, and $2000 \mathrm{mg} / \mathrm{L}$, respectively. The mixture was stirred at $150 \mathrm{rpm}$ for $12 \mathrm{~h}$. After centrifuging, the precipitates were collected and dried at $60{ }^{\circ} \mathrm{C}$. The samples were denoted as 3S-LDO_MO $\mathrm{M}_{20}$, 3S-LDO_MO ${ }_{1000}$, and 3S-LDO_MO ${ }_{2000}$, respectively. 


\section{Characterization}

142

143

The morphology of as-prepared material was determined on transmission electron microscopy (TEM, JEOL-2010) with high-resolution TEM (HRTEM, JEOL-2010) image at an accelerating voltage of $200 \mathrm{kV}$, and scanning electron microscope (SEM, JSM 6701F) equipped with energy-dispersive X-ray spectroscopy (EDS) mapping. The chemical composition and crystallographic structure were carried out by using an X-ray powder diffractometer (XRD, D8 ADVANCE X) equipped with $\mathrm{Cu} \mathrm{K \alpha}(40 \mathrm{kV}, 40 \mathrm{~mA})$ radiation. The elemental chemical states were characterized by Fourier transformed infrared spectroscopy (FT-IR, TNA 370) and X-ray photoelectron spectroscopy (XPS, ESCALAB 250XI). The specific surface area and pore diameter of the samples were analyzed by the Brunauer-Emmett-Tellersurface method measured using an ASAP 2460 surface analyzer.

\section{Recycle experiments}

The reusability and stability of 3S-LDO were evaluated by adsorption-regeneration experiments. The protocol of MO adsorption was the same as that in section 2.3. The regeneration was carried out by calcinating the used adsorbent after reaction in a muffle furnace at $700{ }^{\circ} \mathrm{C}$ for $4 \mathrm{~h}$ in air. Then the collected material was reused for MO adsorption in the succeeding cycles. 
The phase compositions of 3S-LDH precursor and 3S-LDO were detected by the XRD technique. As displayed in Fig. 1a, a set of characteristic peaks of $\mathrm{MgAl} \mathrm{LDH}$ with the $d$-spacing value $\left(d_{(003)}\right)$ of $2.72 \mathrm{~nm}$ as well as the broad peak assigned to SDS located at $20.5^{\circ}$ (JCPDS NO. 39-1996) can be observed for the 3S-LDH sample. This affirmed that the as-prepared precursor was the organic MgAl LDH loaded with SDS, in good agreement with previous literatures ( $\mathrm{Li}$ et al. 2008; Zhang et al. 2019b). After calcination, a clear transformation of the crystalline phase from LDH to $\mathrm{LDO}\left(\mathrm{MgAl}_{2} \mathrm{O}_{4}\right.$, marked with green) was detected in the $3 \mathrm{~S}$ LDO (Fig. 1a) (Lei et al. 2017). Moreover, several new $\mathrm{MgSO}_{4}$ peaks with (021), (111), (022), (131), (042), and (231) crystalline planes (JCPDS NO. 21-0546) were identified in the 3S-LDO, while the relative organic phases of SDS disappeared. Such phenomenon suggested that the SDS was completely converted to sulfate group loaded on LDO during calcination. 1b). For the 3S-LDH, the wide bands centered at 3530,1639 and $445 \mathrm{~cm}^{-1}$ were ascribed to the

173 hydroxyl group, the interlayer water molecules, and the O-M-O band, respectively (Ji et al. 174 2018). And two apparent characteristic $\mathrm{S}=\mathrm{O}$ bands of SDS emerged at 1463 and $1210 \mathrm{~cm}^{-1}$ 175 (Zhang et al. 2019b). After calcination, the characteristic peak of hydroxyl groups and interlayer water all diminished. Meanwhile, O-M-O band of 3S-LDH was divided into several new peaks

177 corresponding to $\mathrm{M}-\mathrm{O}(\mathrm{M}: \mathrm{Mg}$ or $\mathrm{Al})$ at the low wavenumber region $\left(400-800 \mathrm{~cm}^{-1}\right)$. The results 178 affirmed that the precursor LDH was dehydrated to form LDO during the calcination process 
179 (Nath and Dolui 2018). Notably, the SDS peaks vanished in1463 and $1210 \mathrm{~cm}^{-1}$ accompanying 180 by the occurrence of a sharp peak at $1114 \mathrm{~cm}^{-1}$ ascribed to the $\mathrm{SO}_{4}{ }^{2-}$ in the $3 \mathrm{~S}-\mathrm{LDO}$ (Yu et al. 181 2020). The SDS in 3S-LDH was successfully transformed to $\mathrm{SO}_{4}{ }^{2-}$. XPS measurement was further conducted to investigate the chemical composition and chemical state of elements and surfaces in the 3S-LDO. The survey XPS spectrum (Fig. 1c) demonstrated the presence of $\mathrm{O}, \mathrm{Al}, \mathrm{Mg}$, and $\mathrm{S}$ elements in 3S-LDO. In the high-resolution $\mathrm{Mg}$ 1s XPS spectrum (Fig. 1d), two peaks emerged at approximately $1304.5 \mathrm{eV}$ ascribed to $\mathrm{Mg}-\mathrm{O}$ bond derived from $\mathrm{MgAl}_{2} \mathrm{O}_{4}$ and $1303.2 \mathrm{eV}$ belonged to the $\mathrm{Mg}-\mathrm{S}$ bond (Yuan et al. 2014). Notably, the $\mathrm{S}$ was attributed to the $\mathrm{SO}_{4}{ }^{2-}$ group as demonstrated by the high-resolution $\mathrm{S} 2 \mathrm{p}$ and O 1s spectra (Fig. 1e and f) (Li et al. 2020; Zhang et al. 2016). Therefore, we could speculate that the $\mathrm{SO}_{4}{ }^{2-}$ bonded to $\mathrm{Mg}^{2+}$ from $\mathrm{MgAl}_{2} \mathrm{O}_{4}$ via the formation of the $\mathrm{Mg}-\mathrm{S}$ bond to be anchored in 3S-LDO. To further affirm the hypothesis, we added $0.01 \mathrm{~g}$ 3S-LDO into $10 \mathrm{~mL}$ deionized water to investigate the release of $\mathrm{SO}_{4}{ }^{2-}$ after $12 \mathrm{~h}$. As described in Table S1, it was found that only $4.41 \mathrm{mg} / \mathrm{L}$ of $\mathrm{SO}_{4}{ }^{2-}$ was released into the solution. Theoretically, the amount of $\mathrm{SO}_{4}{ }^{2-}$ in 3S-LDO should be calculated as $295.16 \mathrm{mg} / \mathrm{L}$ according to the atomic percentage of $\mathrm{S}$ from $3 \mathrm{~S}-$ of the actual release value, indicating that $\mathrm{SO}_{4}{ }^{2-}$ in $3 \mathrm{~S}-\mathrm{LDO}$ was almost insoluble in water. the typical 3D structure of LDO (Hong et al. 2020). HRTEM image (Fig. 2c) observed the lattice fringes with the interplanar spacings of $0.258 \mathrm{~nm}$, which linked to the (311) plane of 
$\mathrm{LDO}\left(\mathrm{MgAl}_{2} \mathrm{O}_{4}\right)$. Element mapping images in Fig. $2 \mathrm{~d}$ presented that not only $\mathrm{Mg}, \mathrm{Al}$, and $\mathrm{O}$ of LDO but also S elements were homogeneously distributed on the 3S-LDO's surface, confirming the construction of sulfate-functionalized LDO.

\section{Adsorption of MO on 3S-LDO}

\section{Effect of adsorbent dosage}

Fig. 3a showed the effect of adsorbent dosage $(0.1-1.0 \mathrm{~g} / \mathrm{L})$ on the MO removal. With the dosage raising, the adsorption capacity of 3S-LDO decreased, whereas the removal efficiency initially ascended dramatically due to the increase of the unsaturated adsorption sites (Maity and Ray 2017), until reaching a plateau at $0.3 \mathrm{~g} / \mathrm{L}$. Considering the removal efficiency and cost of wastewater treatment applications, the dosage of $3 \mathrm{~S}-\mathrm{LDO}$ was set as $0.3 \mathrm{~g} / \mathrm{L}$ in the subsequent experiments. It is worth noting that the obtained adsorption amount and efficiency kept a high level (3452.37 mg/g and 95.41\%) at this low 3S-LDO dosage (only $0.3 \mathrm{~g} / \mathrm{L}$ ) with the MO concentration of $1000 \mathrm{mg} / \mathrm{L}$, indicating that 3S-LDO was an excellent adsorbent toward MO.

\section{Effect of initial concentration and adsorption isotherm}

Adsorption isotherms were employed to investigate the adsorption capacities of 3S-LDO at various initial $\mathrm{MO}$ concentrations $\left(C_{0}\right)$ under 25,35 , and $45^{\circ} \mathrm{C}$, respectively. As is apparent from Fig. 3b, MO removal exhibited a nearly linear relationship with $C_{0}$ and reached adsorption equilibrium at $2000 \mathrm{mg} / \mathrm{L}$. While for the removal rate (Fig. 3c), it showed an extreme uptrend at initial low concentration $(\leqslant 400 \mathrm{mg} / \mathrm{L})$, followed by a temporary plateau, and gradually 
dropping when the MO concentration was higher than $1000 \mathrm{mg} / \mathrm{L}$. Compared to the removal efficiency of 3D-LDO (Fig. 3d), it was different from 3D-LDO, implying the involvement of other interactions for MO removal besides LDO. Additionally, the adsorption capacities of 3SLDO decreased with the elevated temperature. The result suggested that lower temperature favored the MO removal by 3S-LDO, which was the desirable attribute for water treatment as well (Zhao et al. 2014).

The Langmuir (Eq. (3)) and Freundlich (Eq. (4)) models were employed to further analyze the obtained adsorption data (Demirçivi 2018). Based on the discussion on the impact of initial concentration (Fig. 3c), the adsorption isotherms model was examined in the concentration range of $800-4000 \mathrm{mg} / \mathrm{L}$ for $3 \mathrm{~S}-\mathrm{LDO}$.

$$
\begin{aligned}
& \frac{C_{\mathrm{e}}}{q_{\mathrm{e}}}=\frac{1}{b q_{\mathrm{m}}}+\frac{C_{\mathrm{e}}}{q_{\mathrm{m}}} \\
& \ln q_{\mathrm{e}}=\ln K_{\mathrm{F}}+\frac{1}{\mathrm{n}} \ln C_{\mathrm{e}}
\end{aligned}
$$

where $C_{\mathrm{e}}(\mathrm{mg} / \mathrm{L})$ and $q_{\mathrm{e}}(\mathrm{mg} / \mathrm{g})$ are the equilibrium adsorption concentration and capacity, respectively; $b(\mathrm{~L} / \mathrm{mg})$ is the Langmuir isothermal constant and $q_{\mathrm{m}}(\mathrm{mg} / \mathrm{g})$ is the maximum adsorption capacity; $K_{\mathrm{F}}\left[(\mathrm{mg} / \mathrm{g}) \cdot(\mathrm{L} / \mathrm{mg})^{1 / \mathrm{n}}\right]$ and $n$ are the Freundlich empirical constants and heterogeneity factor, respectively.

The fitting results were presented in Fig. S2 and Table 1. According to the value of the correlation coefficients $\left(R^{2}\right)$, the Langmuir model gave a better fit than the Freundlich model, suggesting the occurrence of monolayer adsorption in the investigated concentration ranges (Zhang et al. 2019c). Notably, the theoretical maximum adsorption amounts of 3S-LDO calculated from the Langmuir model were much higher than that of 3D-LDO under the same conditions, indicative of the crucial role of the sulfate group in 3S-LDO on enhancing MO 
adsorption. Besides, it should also be pointed out that the $q_{\mathrm{m}}(4340.71 \mathrm{mg} / \mathrm{g})$ of 3 S-LDO at $25{ }^{\circ} \mathrm{C}$ was much superior to those of the reported materials (Table 2), highlighting the exceptional performance of 3S-LDO for MO.

\section{Thermodynamic analysis}

The temperature effect on the MO adsorption by 3S-LDO was explored by thermodynamic analysis. Three basic thermodynamic parameters, including standard enthalpy change $\left(\Delta H^{0}\right)$, entropy change $\left(\Delta S^{0}\right)$ and Gibbs free energy change $\left(\Delta G^{0}\right)$, were employed and calculated as follows (Wu et al. 2018).

$$
\begin{gathered}
K_{\mathrm{d}}=\frac{q_{\mathrm{e}}}{C_{\mathrm{e}}} \\
\Delta G^{0}=-R T \ln K_{\mathrm{d}} \\
\ln K_{\mathrm{d}}=\frac{\Delta S^{0}}{R}-\frac{\Delta H^{0}}{R T}
\end{gathered}
$$

where $K_{\mathrm{d}}(\mathrm{L} / \mathrm{g})$ is the equilibrium constant at various temperatures, $R(8.314 \mathrm{~J} /(\mathrm{mol} \cdot \mathrm{K}))$ is the universal gas constant and $T(\mathrm{~K})$ is the system temperature; The values of $\Delta H^{0}$ and $\Delta S^{0}$ are obtained from the slope and the intercept of $\ln K_{\mathrm{d}}$ (Fig. 3e). The thermodynamic parameters were listed in Table S2.

The $\Delta H^{0}$ values of $3 \mathrm{~S}-\mathrm{LDO}$ was $-13.79 \mathrm{~kJ} / \mathrm{mol}$, indicating that $\mathrm{MO}$ adsorption on the sample was exothermic (Wang et al. 2015). The negative $\Delta S^{0}$ values demonstrated that the freedom feature of the adsorption systems became lower after adsorption, which ascribed to the restriction of molecular motion on the surface of adsorbents (Wang et al. 2015). From the negative values of $\Delta G^{0}$ for 3S-LDO in all temperatures, it can be concluded that the reaction process was spontaneous and favorable. In addition, the $\Delta G^{0}$ values increased with increasing 
temperature confirming that the lower temperature favored the MO adsorption on 3S-LDO (Zhao et al. 2014), which was per the results of adsorption isotherm (Fig. 3b).

\section{Effect of contact time and adsorption kinetics}

Given the significant influence of initial MO concentration on 3S-LDO (Fig. 3c), the kinetic was conducted at three different initial MO concentrations $(20,1000,2000 \mathrm{mg} / \mathrm{L})$. As time increased (Fig. 3f), the adsorption amount had a trivial increase at low MO concentration (20 mg/L), while the adsorption was very fast when the $\mathrm{MO}$ concentration $\geq 1000 \mathrm{mg} / \mathrm{L}$, with the adsorption capacity up to $2720.27 \mathrm{mg} / \mathrm{g}$ in the first 1 minute (Fig. $3 \mathrm{f}$ and inset). These distinct kinetic results at low and high MO concentration verified that the removal process relied on initial dye concentration. And the fast-kinetic at high MO concentration $(\geq 1000 \mathrm{mg} / \mathrm{L})$ placed 3S-LDO in a notable position among advanced materials for MO removal. By contrast, the adsorption rate of 3D-LDO was much slower than 3S-LDO (Fig. S3), inferring that the rapid adsorption performance of 3S-LDO was also relative with the sulfate group.

To further investigate the detailed adsorption dynamics, the pseudo-first-order model (Eq. (8)) and pseudo-second-order model (Eq. (9)) were used to simulate the experimental data. The two kinetic models were expressed as follows (Wang et al. 2015):

$$
\begin{aligned}
& \ln \left(q_{\mathrm{e}}-\mathrm{q}_{\mathrm{t}}\right)=\ln q_{\mathrm{e}}-k_{1} t \\
& \frac{t}{q_{\mathrm{t}}}=\frac{1}{k_{2} q_{\mathrm{e}}^{2}}+\frac{t}{q_{\mathrm{e}}}
\end{aligned}
$$

where $q_{\mathrm{e}}(\mathrm{mg} / \mathrm{g})$ and $q_{\mathrm{t}}(\mathrm{mg} / \mathrm{g})$ are the adsorption capacity at equilibrium and time $\mathrm{t}(\mathrm{min})$, respectively; $k_{1}\left(\mathrm{~min}^{-1}\right)$ and $k_{2}[\mathrm{~g} /(\mathrm{mg} \cdot \mathrm{min})]$ are the kinetic adsorption rate constants of the pseudo-first-order and pseudo-second-order models, respectively. 
in Table 3. From the $R^{2}$ of these models, the pseudo-second-order model was more suitable to

287 describe the MO removal, with the closer calculated $q_{\mathrm{e}, \text { cal }}$ to the values of experiments $\left(q_{\mathrm{e}, \mathrm{exp}}\right)$.

288 This unveiled that chemisorption was the primary adsorption mechanism (Yao et al. 2017).

289 Compared to $3 \mathrm{D}-\mathrm{LDO}\left(1.43 \times 10^{-3} \mathrm{~g} /(\mathrm{mg} \cdot \mathrm{min})\right)$ in Table 3 , the $k_{2}$ for $3 \mathrm{~S}-\mathrm{LDO}\left(5.94 \times 10^{-3}\right.$

$290 \mathrm{~g} /(\mathrm{mg} \cdot \mathrm{min}))$ was much higher, i.e., the MO adsorption on 3S-LDO was faster than 3D-LDO,

291 proving again that the important role of sulfate group in the enhancement of MO adsorption 292 rate.

\section{Adsorption mechanism}

Generally, the specific surface area (SSA) of adsorbent has a positive influence on contaminants removal (Sun et al. 2020), that is, the higher SSA is beneficial for contaminants removal (Li et al. 2020). As depicted in Fig. S5, 3S-LDO exhibited a typical type-IV isotherm with a narrow hysteresis loop (H3 type) like that of 3D-LDO (Siyasukh et al. 2018). Interestingly, the value of SSA for 3S-LDO was markedly lower than that of 3D-LDO (Table S3), while the adsorption capacity of 3S-LDO (4340.71 $\mathrm{mg} / \mathrm{g})$ was superior to 3D-LDO ( $3594.46 \mathrm{mg} / \mathrm{g}$ ) in Fig. 3b. It can be implied that the SSA was not the dominant reason leading to the excellent removal performance of 3S-LDO toward MO. LDO before and after MO removal were investigated at various dye concentrations (20, 1000, 
products, such as 1606 and $1518 \mathrm{~cm}^{-1}$ (the $\mathrm{C}=\mathrm{C}$ stretching vibration of benzene ring structure), 1370 and $1420 \mathrm{~cm}^{-1}$ (the $\mathrm{N}=\mathrm{N}$ stretching vibration) (Han et al. 2016), 1187 and $1034 \mathrm{~cm}^{-1}$ (the asymmetric and symmetric stretching vibrations of $\mathrm{SO}_{3}^{-}$group in $\mathrm{MO}$ ), $1117 \mathrm{~cm}^{-1}$ (the $\mathrm{C}-\mathrm{N}$ stretching vibration) (Yao et al. 2017). With the increasing MO concentration, the intensity of $\mathrm{SO}_{3}{ }^{-}$peak in $\mathrm{MO}$ enhanced while that of $\mathrm{SO}_{4}{ }^{2-}$ bond in $3 \mathrm{~S}-\mathrm{LDO}$ became weak, indicating that the $\mathrm{SO}_{4}{ }^{2-}$ of $3 \mathrm{~S}-\mathrm{LDO}$ reacted with $\mathrm{MO}$ (Fig. 4a). In addition, the $\mathrm{M}-\mathrm{O}(\mathrm{M}=\mathrm{Mg}$ and $\mathrm{Al})$ bonds at $400-900 \mathrm{~cm}^{-1}$ in the FT-IR spectra shifted or disappeared in all concentrations (Fig. $4 \mathrm{~b}$ ), implying that the complexation might exist in MO removal due to metal ions (i.e., $\mathrm{Mg}^{2+}$ and $\mathrm{Al}^{3+}$ ) from 3S-LDO complexed with $\mathrm{SO}_{3}{ }^{-}$groups of MO (Lyu et al. 2020; Yao et al. 2017; Zhang et al. 2018). And the obvious shift of Mg 1s and Al 2p XPS spectra before and after MO adsorption also proved the complexation (Fig. 4c) (Peng et al. 2014). The interaction between $\mathrm{SO}_{4}{ }^{2-}$ and $\mathrm{MO}$ also was further examined by the XPS spectra of $\mathrm{S} 2 \mathrm{p}$ and $\mathrm{N} 1 \mathrm{~s}$ (Fig. $4 \mathrm{~d}$ and e). The obvious redshift of $\mathrm{SO}_{4}{ }^{2-}$ peak and blueshift of $\mathrm{N}=\mathrm{N}$ peak was observed with the increase of $\mathrm{MO}$ concentration (Wang et al. 2018). Generally, the $\mathrm{S}=\mathrm{O}$ bond from $\mathrm{SO}_{4}{ }^{2-}$ with a covalent double bond exhibited stronger affinity towards electrons (Zhao et al. 2011), while the $\mathrm{N}=\mathrm{N}$ double bond in MO as an electron rich bond could provide the electrons (Han et al. 2016). It could be illustrated that the electron-donor-acceptor (EDA) interaction occurred between the $\mathrm{N}=\mathrm{N}$ double bond in $\mathrm{MO}$ and the $\mathrm{S}=\mathrm{O}$ bond from $\mathrm{SO}_{4}{ }^{2-}$ of 3S-LDO (Sun et al. 2020; Yuan et al. 2020). Besides, the MO peaks, i.e., $\mathrm{SO}_{3}^{-}$in $\mathrm{S} 2 \mathrm{p}$ spectrum and $-\mathrm{N}\left(\mathrm{CH}_{3}\right)_{2}$ in $\mathrm{N} 1$ s spectrum, appeared in high concentrations of $\mathrm{MO}$, which indicated that the EDA interaction was reinforced with the increase of MO concentration. (Jiang et al. 2020; Zhang et al. 2019b).

327 Especially, the N-S bond was checked at 400.0/400.2 eV in N 1s spectrum, further confirming 
the strong interaction between the $\mathrm{SO}_{4}{ }^{2-}$ and $\mathrm{MO}$ (Setiawan et al. 1985).

Such above-mentioned interactions were expounded by the XRD technique as well (Fig. 4f). The partial disappearance of the $\mathrm{MgSO}_{4}$ peaks in 3S-LDO after adsorption in all concentrations $(20,1000$, and $2000 \mathrm{mg} / \mathrm{L})$ affirmed that both $\mathrm{Mg}^{2+}$ and $\mathrm{SO}_{4}{ }^{2-}$ participated in the MO removal via complexation and EDA interaction, respectively (Rong et al. 2020; Yao et al. 2017). Noticeably, additional peaks at $2 \theta=4.54^{\circ}, 7.39^{\circ}, 9.17^{\circ}$, and $61.13^{\circ}$ linked to the (003), (006), (009), and (110) planes of LDH were observed at the MO concentration of $2000 \mathrm{mg} / \mathrm{L}$, illustrating that part of MO was adsorbed accompanying with rehydration of LDH via "memory effect" at higher concentration. (Jia and Liu 2019). And the process of inserting into interlayers also caused the change of layer space, resulting in many new peaks appeared at the $2 \theta$ values of $15-30^{\circ}$ (Yao et al. 2017).

Apart from the EDA interaction, complexation, and "memory effect", other mechanisms such as van der Waals, hydrogen bonding, and electrostatic forces (Coulomb forces) were generally introduced in MO removal as numerous researches reported (Yao et al. 2017; Zhang et al. 2019b). In this work, the van der Waals interaction was not considered in controlling the MO adsorption because of the chemisorption of 3S-LDO determined by adsorption kinetic (Fig. S4). Likewise, the hydrogen bonding played a negligible role, judging by the unchanged position of O-H peak in 3S-LDO after MO adsorption (FT-IR, Fig. 4a). To investigate the contribution of electrostatic interaction, the zeta potential of 3S-LDO was examined as shown in Fig. S6a. The values of zeta potential nearly maintained zero in the range of 3-11 which indicated the neutral surface charge of 3S-LDO. That is to say, there was no electrostatic interaction between 3S-LDO and MO, in agreement with the results of the $\mathrm{pH}$ effect in Fig. 
S6b.

Based on the aforementioned analyses, the removal mechanisms of MO on 3S-LDO were

352 comprehensively summarized in Fig. 5. The removal pathway of MO was determined by the initial concentrations. In all concentrations of MO, the removal by 3S-LDO was mainly associated with the sulfate groups (i.e., EDA interaction) and metal complexation, and the EDA interaction was enhanced with the increase of MO concentration. When the concentration increased to $2000 \mathrm{mg} / \mathrm{L}$, the "memory effect" of LDO also played a role in MO removal besides the two interactions discussed above.

\section{Reusability and ionic strength study}

The reusability of adsorbent is a critical factor for evaluating the practical applicability in wastewater treatment. In order to test the reusability of 3S-LDO, the consecutive adsorptionregeneration experiments were repeated five times, with the $\mathrm{MO}$ concentration of $1000 \mathrm{mg} / \mathrm{L}$. As shown in Fig. 6a, the adsorption capacity of MO still maintained as high as $3100 \mathrm{mg} / \mathrm{g}$ after five cycles. The corresponding removal efficiency was $\sim 91 \%$. These results suggested that the prepared 3S-LDO exhibited good stability and reusability for the removal of MO.

In addition, the effect of competitive anions $\left(\mathrm{Cl}^{-}, \mathrm{NO}_{3}^{-}\right.$, and $\left.\mathrm{CO}_{3}{ }^{2-}\right)$ with different concentrations on the $\mathrm{MO}(1000 \mathrm{mg} / \mathrm{L})$ adsorption was also investigated to identify the feasibility of 3S-LDO in environmental applications. The results demonstrated that $\mathrm{Cl}^{-}$and $\mathrm{NO}_{3}^{-}$displayed a negligible effect on the MO adsorption $\left(q_{\text {anion }} / q_{0}>98 \%\right)$ in all ion concentrations (Fig. 6b). However, the removal efficiency of MO exhibited a $15 \%$ decrease in the presence of $\mathrm{CO}_{3}{ }^{2-}(0.02 \mathrm{M})$ and then kept a stable value at $72 \%$ in the concentration range 
371

372

373

of $0.04-0.10 \mathrm{M}$. The decreased removal efficiency was possible because $\mathrm{CO}_{3}{ }^{2-}$ possessed a stronger affinity in solution as compared to other anions, thus competing with $\mathrm{MO}$ for adsorption sites (Lei et al. 2017). On the other hand, $\mathrm{CO}_{3}{ }^{2-}$ would combine with metal ions (i.e., $\mathrm{Mg}^{2+}$ and $\left.\mathrm{Al}^{3+}\right)$ from LDO to generate insoluble $\mathrm{MgCO}_{3}$ and $\mathrm{Al}(\mathrm{OH})_{3}$, which weakened the surface complexation between the metal ions and MO, thereby leading to a slight decrease in the removal of MO. Notably, the removal capacity of 3S-LDO for MO remained at a high level $\left(\geq 2596 \mathrm{mg} / \mathrm{g}\right.$ ) when a large number of $\mathrm{CO}_{3}{ }^{2-}$ were present. This result confirmed that the EDA interaction associated with $\mathrm{SO}_{4}{ }^{2-}$ played a vital role in $\mathrm{MO}$ removal rather than complexation.

\section{Selective adsorption performance of 3S-LDO}

Given that the authentic dye wastewater contains various kinds of dyes, which might compete with target dyes, it is essential to explore the selective adsorption ability of 3S-LDO toward MO in the coexistence with common dyes (Ghaffar et al. 2018). Methylene blue (MB, cationic dye) was selected as competitive dyes because it has different functional groups, surface charges and sizes with MO (Du et al. 2017). As shown in Fig. 7a, the color of the dye mixture solution was dark green after mixing the same volume of MO (100 ppm, the orange vial in Fig. 7a) and MB (50 ppm, the blue vial in Fig. 7a). When 3S-LDO was added to the mixture solution, it clearly can be seen that the color of the mixture solution became blue within $1 \mathrm{~h}$, which was closed to the color of pure MB solution. This phenomenon suggested the high selectivity of 3S-LDO toward MO, which was also confirmed by UV-vis spectra scan (Fig. 7b). After adsorption, the adsorption peak of MO decreased significantly, while that of MB was almost unchanged, verifying the specific adsorption of 3S-LDO for MO. 
The MO removal efficiency in three different types of real water samples, including tap water, river water from the Ganjiang River and industrial wastewater from a factory in Jiujiang, Jiangxi province, China, was also explored to further assess the practical application of 3SLDO. As shown in Fig. 8, the adsorption processes of MO in tap water and river water showed a fair degree of agreement with the adsorption of MO in deionized water. Even in industrial wastewater, the adsorption efficiency of $\mathrm{MO}$ could reach up to $73 \%$. In view of these encouraging results, it is reasonable to deduce that the 3S-LDO sample can serve as a promising adsorbent for authentic dyeing effluents.

\section{Conclusion}

In summary, a novel three-dimensional sulfate-functionalized MgAl-layered double oxide (3S-LDO) derived from organic layered wastes was synthesized as a superior and recyclable adsorbent for efficient MO removal. Isotherm and kinetic results unveiled the immense MO capacity of $4340.71 \mathrm{mg} / \mathrm{g}$ at $298 \mathrm{~K}$ with a fast removal rate-limited in 1 hour, which was much higher than the most known adsorbents. The thermodynamic study illustrated the spontaneous and exothermic reaction between MO the 3S-LDO. Multiple characterizations were 408 synthetically conducted, unveiling that the superior MO removal was associated with sulfate group in 3S-LDO in virtue of the electron-donor-acceptor (EDA) interaction between the $\mathrm{S}=\mathrm{O}$

$410\left(\mathrm{SO}_{4}{ }^{2-}\right)$ and $\mathrm{N}=\mathrm{N}(\mathrm{MO})$. Besides, the "memory effect" and surface complexation of 3S-LDO 411 enhanced the MO adsorption. More importantly, the recycle experiments and coexisting tests 412 highlighted the outstanding reusability as well as explicit selectivity of 3S-LDO. Even in the 
413 authentic water matrices, 3S-LDO exhibited excellent MO removal with a high removal

414 efficiency of $80 \%$. This work is expected to open a new avenue for the reuse/recycling of

415 organic waste to construct functional adsorbent with enormous capacity, excellent reusability,

416 and high selectivity for organic wastewater treatment.

417 Acknowledgments

418 We would like to thank the support of the Analysis and Test Center of Nanchang University

419 for infrastructure and morphology characterizations.

\section{Funding}

This project is financially supported by the National Natural Science Foundation of China

Province No. 2019BCJ22002, the Natural Science Foundation of Jiangxi Province No.

01.

\section{Author's contribution}




\section{Data availability}

The datasets used and/or analysed during the current study are available from the corresponding author on reasonable request.

\section{Declarations}

\section{Ethical approval Not Applicable.}

Consent to participate Not Applicable.

Consent to publication Not Applicable.

Competing interests The authors declare that they have no competing interests.

\section{References}

Cao Y, Wang YX, Zhang XY, Cai XG, Li ZH, Li GT (2019) Facile synthesis of 3D Mg-Al layered double oxide microspheres with ultra high adsorption capacity towards methyl orange. Mater Lett 257:126695. https://doi:10.1016/j.matlet.2019.126695

Chen M, Li S, Li L, Jiang L, Ahmed Z, Dang Z, Wu P (2021) Memory effect induced the enhancement of uranium (VI) immobilization on low-cost MgAl-double oxide: Mechanism insight and resources recovery. J Hazard Mater 401:123447. https://doi:https://doi.org/10.1016/j.jhazmat.2020.123447

Demirçivi P (2018) Synthesis and characterization of Zr(IV) doped immobilized cross-linked chitosan/perlite composite for acid orange II adsorption. Int J Biol Macromol 118:340-346. https://doi:https://doi.org/10.1016/j.ijbiomac.2018.06.065

Du XD, Wang CC, Liu J, Zhao XD, Zhong J, Li YX, Li J, Wang P (2017) Extensive and selective adsorption of ZIF-67 towards organic dyes: Performance and mechanism. J Colloid Interface Sci 506:437-441. https://doi:https://doi.org/10.1016/j.jcis.2017.07.073

Feng L, Qin Z, Huang Y, Peng K, Wang F, Yan Y, Chen Y (2020) Boron-, sulfur-, and phosphorus-doped graphene for environmental applications. Sci Total Environ 698:134239. https://doi:10.1016/j.scitotenv.2019.134239 

nanoparticles decorated on activated coke via a facile preparation for efficient catalytic reduction of nitrophenols and azo dyes. Appl Surf Sci 473:578-588. https://doi:https://doi.org/10.1016/j.apsusc.2018.12.207

Ghaffar A, Zhang L, Zhu X, Chen B (2018) Porous PVdF/GO Nanofibrous Membranes for Selective Separation and Recycling of Charged Organic Dyes from Water. Environ Sci Technol 52:4265-4274. https://doi:10.1021/acs.est.7b06081

Gurav R, Bhatia SK, Choi TR, Choi YK, Kim HJ, Song HS, Lee SM, Lee Park S, Lee HS, Koh J, Jeon JM, Yoon JJ, Yang YH (2021) Application of macroalgal biomass derived biochar and bioelectrochemical system with Shewanella for the adsorptive removal and biodegradation of toxic azo dye. Chemosphere 264:128539. https://doi:10.1016/j.chemosphere.2020.128539

Han J, Zeng HY, Xu S, Chen CR, Liu XJ (2016) Catalytic properties of CuMgAlO catalyst and degradation mechanism in CWPO of methyl orange. Appl Catal, A 527:72-80. https://doi:10.1016/j.apcata.2016.08.015

Hong YC, Zhou HY, Xiong ZK, Liu Y, Yao G, Lai B (2020) Heterogeneous activation of peroxymonosulfate by CoMgFe-LDO for degradation of carbamazepine: Efficiency, mechanism and degradation pathways. Chem Eng J 391:123604. https://doi:10.1016/j.cej.2019.123604

Hu H, Wageh S, Al-Ghamdi AA, Yang S, Tian Z, Cheng B, Ho W (2020) NiFe-LDH nanosheet/carbon fiber nanocomposite with enhanced anionic dye adsorption performance. Appl Surf Sci 511:145570. https://doi:10.1016/j.apsusc.2020.145570

Ji F, Li J, Cui XL, Liu J, Bing XM, Song P (2018) Hierarchical C-doped BiPO4/ZnCoAl-LDO hybrid with enhanced photocatalytic activity for organic pollutants degradation. Appl Clay Sci 162:182-191. https://doi:10.1016/j.clay.2018.06.012

Ji Y, Zhang W, Yang H, Ma F, Xu F (2021) Green synthesis of poly(pyrrole methane) for enhanced adsorption of anionic and cationic dyes from aqueous solution. J Colloid Interface Sci 590:396-406. https://doi:https://doi.org/10.1016/j.jcis.2021.01.073

Jia YH, Liu ZH (2019) Preparation of borate anions intercalated MgAl-LDHs microsphere and its calcinated product with superior adsorption performance for Congo red. Colloids Surf, A 575:373-381. https://doi:10.1016/j.colsurfa.2019.05.032

Jiang Z, Yan L, Wu J, Liu X, Zhang J, Zheng Y, Pei Y (2020) Low-temperature synthesis of carbonate-intercalated NixFe-layered double hydroxides for enhanced adsorption properties. Appl Surf Sci 531:147281. https://doi:10.1016/j.apsusc.2020.147281

Kelm MAP, da Silva Júnior MJ, de Barros Holanda SH, de Araujo CMB, de Assis Filho RB, Freitas EJ, dos Santos DR, da Motta Sobrinho MA (2019) Removal of azo dye from water via adsorption on biochar produced by the gasification of wood wastes. Environ Sci Pollut Res 26:28558-28573. https://doi:10.1007/s11356-018-3833-x

Khaled B, Nassira Z, Imene H (2020) Eco-friendly synthesis of self-regenerative low-cost biosorbent by the incorporation of $\mathrm{CuO}$ : a photocatalyst sensitive to visible light irradiation for azo dye removal. Environ Sci Pollut Res 27:31074-31091. https://doi:10.1007/s11356020-09364-1

Kundu S, Naskar MK (2019) Al-Mg-Ca-Layered Double Oxides for Efficient Removal of As(V) from Water: The Role of Amides. J Chem Eng Data 64:1594-1604. https://doi:10.1021/acs.jced.8b01154 
Laipan M, Zhu R, Chen Q, Zhu J, Xi Y, Ayoko GA, He H (2015) From spent Mg/Al layered double hydroxide to porous carbon materials. J Hazard Mater 300:572-580. https://doi:10.1016/j.jhazmat.2015.07.057

Lei C, Zhu X, Zhu B, Jiang C, Le Y, Yu J (2017) Superb adsorption capacity of hierarchical calcined $\mathrm{Ni} / \mathrm{Mg} / \mathrm{Al}$ layered double hydroxides for Congo red and $\mathrm{Cr}(\mathrm{VI})$ ions. J Hazard Mater 321:801-811. https://doi:10.1016/j.jhazmat.2016.09.070

Li B, He J, Evans DG (2008) Experimental investigation of sheet flexibility of layered double hydroxides: One-pot morphosynthesis of inorganic intercalates. Chem Eng J 144:124-137. https://doi:https://doi.org/10.1016/j.cej.2008.06.031

Li M, Wu G, Liu Z, Xi X, Xia Y, Ning J, Yang D, Dong A (2020) Uniformly coating ZnAl layered double oxide nanosheets with ultra-thin carbon by ligand and phase transformation for enhanced adsorption of anionic pollutants. J Hazard Mater 397:122766. https://doi:10.1016/j.jhazmat.2020.122766

Lv Z, Yang S, Zhu H, Chen L, Alharbi NS, Wakeel M, Wahid A, Chen C (2018) Highly efficient removal of As(V) by using NiAl layered double oxide composites. Appl Surf Sci 448:599608. https://doi:10.1016/j.apsusc.2018.04.162

Lyu HX, Hu K, Fan JS, Ling YXF, Xie ZH, Li J (2020) 3D hierarchical layered double hydroxide/carbon spheres composite with hollow structure for high adsorption of dye. Appl Surf Sci 500:144037. https://doi:10.1016/j.apsusc.2019.144037

Maity J, Ray SK (2017) Competitive Removal of $\mathrm{Cu}(\mathrm{II})$ and $\mathrm{Cd}(\mathrm{II})$ from Water Using a Biocomposite Hydrogel. J Phys Chem B 121:10988-11001. https://doi:10.1021/acs.jpcb.7b08796

Mohtor NH, Othman MHD, Ismail AF, Rahman MA, Jaafar J, Hashim NA (2017) Investigation on the effect of sintering temperature on kaolin hollow fibre membrane for dye filtration. Environ Sci Pollut Res 24:15905-15917. https://doi:10.1007/s11356-017-9341-6

Nath J, Dolui SK (2018) Synthesis of carboxymethyl cellulose-g-poly(acrylic acid)/LDH hydrogel for in vitro controlled release of vitamin B 12. Appl Clay Sci 155:65-73. https://doi:10.1016/j.clay.2018.01.004

Oon YL, Ong SA, Ho LN, Wong YS, Dahalan FA, Oon YS, Teoh TP, Lehl HK, Thung WE (2020) Constructed wetland-microbial fuel cell for azo dyes degradation and energy recovery: Influence of molecular structure, kinetics, mechanisms and degradation pathways. Sci Total Environ 720:137370. https://doi:10.1016/j.scitotenv.2020.137370

Peng Q, Guo J, Zhang Q, Xiang J, Liu B, Zhou A, Liu R, Tian Y (2014) Unique lead adsorption behavior of activated hydroxyl group in two-dimensional titanium carbide. J Am Chem Soc 136:4113-4116. https://doi:10.1021/ja500506k

Riaz N, Hassan M, Siddique M, Mahmood Q, Farooq U, Sarwar R, Khan MS (2020) Photocatalytic degradation and kinetic modeling of azo dye using bimetallic photocatalysts: effect of synthesis and operational parameters. Environ Sci Pollut Res 27:2992-3006. https://doi:10.1007/s11356-019-06727-1

Rong Y, Huang Y, Jin PY, Yang C, Zhong ZH, Dong C, Liang WT (2020) Highly efficient removal of cationic, anionic and neutral dyes by hierarchically porous structured threedimensional magnetic sulfur/nitrogen co-doped reduced graphene oxide nanohybrid. J Water Process Eng 37:101345. https://doi:10.1016/j.jwpe.2020.101345

Setiawan LD, Baumann H, Gribbin D (1985) Surface studies of keratin fibers and related model 
compounds using ESCA. I - intermediate oxidation products of the model compound 1cystine and their hydrolytical behaviour. Surface and Interface Analysis 7:188-195. https://doi:https://doi.org/10.1002/sia.740070406

Siyasukh A, Chimupala Y, Tonanon N (2018) Preparation of magnetic hierarchical porous carbon spheres with graphitic features for high methyl orange adsorption capacity. Carbon 134:207-221. https://doi:10.1016/j.carbon.2018.03.093

Sun ZQ, Zhao L, Liu CH, Zhen YF, Ma J (2020) Fast adsorption of BPA with high capacity based on $\pi-\pi$ electron donor-acceptor and hydrophobicity mechanism using an in-situ sp2 C dominant N-doped carbon. Chem Eng J 381:122510. https://doi:10.1016/j.cej.2019.122510

Tang J, Mu B, Zong L, Zheng M, Wang A (2017) Facile and green fabrication of magnetically recyclable carboxyl-functionalized attapulgite/carbon nanocomposites derived from spent bleaching earth for wastewater treatment. Chem Eng J 322:102-114. https://doi:10.1016/j.cej.2017.03.116

Vu CT, Wu T (2020) Magnetic porous NiLa-Layered double oxides (LDOs) with improved phosphate adsorption and antibacterial activity for treatment of secondary effluent. Water Res 175:115679. https://doi:10.1016/j.watres.2020.115679

Wan D, Wu L, Liu Y, Chen J, Zhao H, Xiao S (2019) Enhanced Adsorption of Aqueous Tetracycline Hydrochloride on Renewable Porous Clay-Carbon Adsorbent Derived from Spent Bleaching Earth via Pyrolysis. Langmuir 35:3925-3936. https://doi:10.1021/acs.langmuir.8b04179

Wang J, Cao M, Jiang C, Zheng Y, Zhang C, Wei J (2018) Adsorption and coadsorption mechanisms of $\mathrm{Hg} 2+$ and methyl orange by branched polyethyleneimine modified magnetic straw. Mater Lett 229:160-163. https://doi:10.1016/j.matlet.2018.07.015

Wang J, Kang DJ, Yu XL, Ge MF, Chen YT (2015) Synthesis and characterization of Mg-FeLa trimetal composite as an adsorbent for fluoride removal. Chem Eng J 264:506-513. https://doi:https://doi.org/10.1016/j.cej.2014.11.130

Wu D, Hu LH, Wang YG, Wei Q, Yan LG, Yan T, Li Y, Du B (2018) EDTA modified $\beta$ cyclodextrin/chitosan for rapid removal of $\mathrm{Pb}$ (II) and acid red from aqueous solution. $\mathrm{J}$ Colloid Interface Sci 523:56-64. https://doi:https://doi.org/10.1016/j.jcis.2018.03.080

Yang C, Xu W, Nan Y, Wang Y, Hu Y, Gao C, Chen X (2020) Fabrication and characterization of a high performance polyimide ultrafiltration membrane for dye removal. J Colloid Interface Sci 562:589-597. https://doi:https://doi.org/10.1016/j.jcis.2019.11.075

Yao W, Yu SJ, Wang J, Zou YD, Lu SS, Ai YJ, Alharbi NS, Alsaedi A, Hayat T, Wang XK (2017) Enhanced removal of methyl orange on calcined glycerol-modified nanocrystallined $\mathrm{Mg} / \mathrm{Al}$ layered double hydroxides. Chem Eng J 307:476-486. https://doi:10.1016/j.cej.2016.08.117 Yu ST, Wu SS, Li L, Ge XP (2020) Upgrading bio-oil from waste cooking oil by esterification using SO42-/ZrO2 as catalyst. Fuel 276:118019. https://doi:10.1016/j.fuel.2020.118019

Yuan C, Zhang Y, Pan Y, Liu X, Wang G, Cao D (2014) Investigation of the intercalation of polyvalent cations $(\mathrm{Mg} 2+, \mathrm{Zn} 2+)$ into $\lambda$-MnO2 for rechargeable aqueous battery. Electrochim Acta 116:404-412. https://doi:10.1016/j.electacta.2013.11.090

Yuan YQ, Majumder S, Yang MH, Guo SR (2020) Recent advances in catalyst-free photochemical reactions via electron-donor-acceptor (EDA) complex process. Tetrahedron Lett 61:151506. https://doi:10.1016/j.tetlet.2019.151506

Zhang H, Chen H, Azat S, Mansurov ZA, Liu XM, Wang JD, Su XT, Wu RL (2018) Super 
adsorption capability of rhombic dodecahedral Ca-Al layered double oxides for Congo red removal. J Alloys Compd 768:572-581. https://doi:10.1016/j.jallcom.2018.07.241

Zhang P, He T, Li P, Zeng X, Huang Y (2019a) New Insight into the Hierarchical Microsphere Evolution of Organic Three-Dimensional Layer Double Hydroxide: The Key Role of the Surfactant Template. Langmuir 35:13562-13569. https://doi:10.1021/acs.langmuir.9b02465 Zhang P, Ouyang SD, Li P, Huang Y, Frost RL (2019b) Enhanced removal of ionic dyes by hierarchical organic three-dimensional layered double hydroxide prepared via soft-template synthesis with mechanism study. Chem Eng J 360:1137-1149. https://doi:10.1016/j.cej.2018.10.179

602 Zhang P, Xiang M, Liu H, Yang C, Deng S (2019c) Novel Two-Dimensional Magnetic Titanium Carbide for Methylene Blue Removal over a Wide pH Range: Insight into Removal Performance and Mechanism. ACS Appl Mater Inter 11:24027-24036. https://doi:10.1021/acsami.9b04222 modified CNTs with Ti(SO4)2 in selective oxidation of dimethyl ether. Catal SciTechnol 6:7193-7202. https://doi:10.1039/c6cy01367h on calcined NiAl hydrotalcite-like compounds. Environ Sci Technol 45:5373-5379. https://doi:10.1021/es200784e

612 Zhao Y, Shao ZY, Chen CL, Hu J, Chen HL (2014) Effect of environmental conditions on the 613 adsorption behavior of $\mathrm{Sr}(\mathrm{II})$ by Na-rectorite. Appl Clay Sci 87:1-6. https://doi:https://doi.org/10.1016/j.clay.2013.11.021

614 

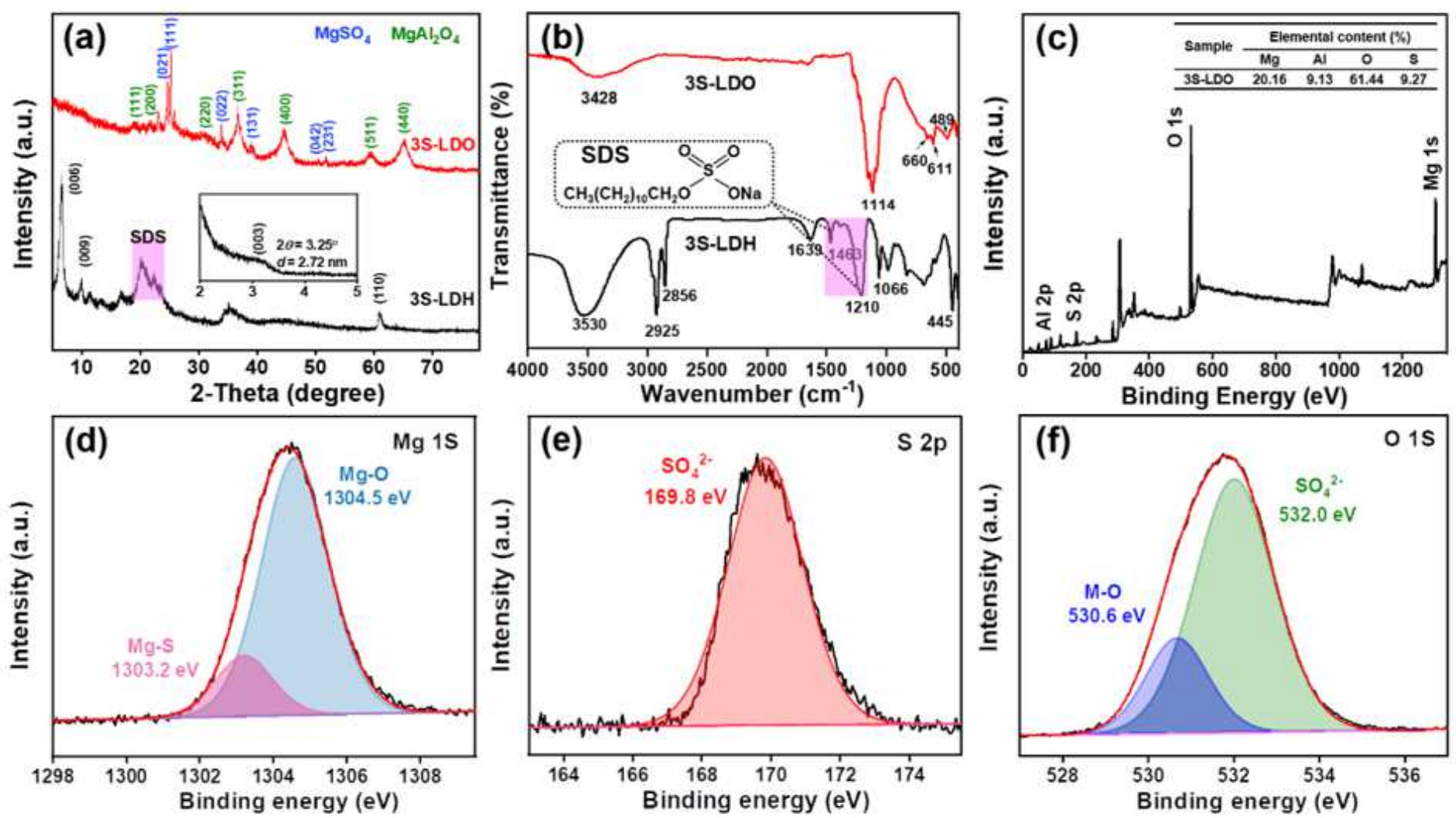

Figure 1

XRD patterns (a) and FT-IR spectra (b) of 3S-LDO and 3D-LDO; The small-angle scattering pattern of 3SLDO below $5^{\circ}$ (a, inset); Survey (c), Mg 1s (d), S 2p (e), and O 1s (f) XPS spectra of 3S-LDO 



Figure 2

SEM (a) and Element mapping images (d) of 3S-LDO; TEM (b) and HRTEM images (c) of 3S-LDO 

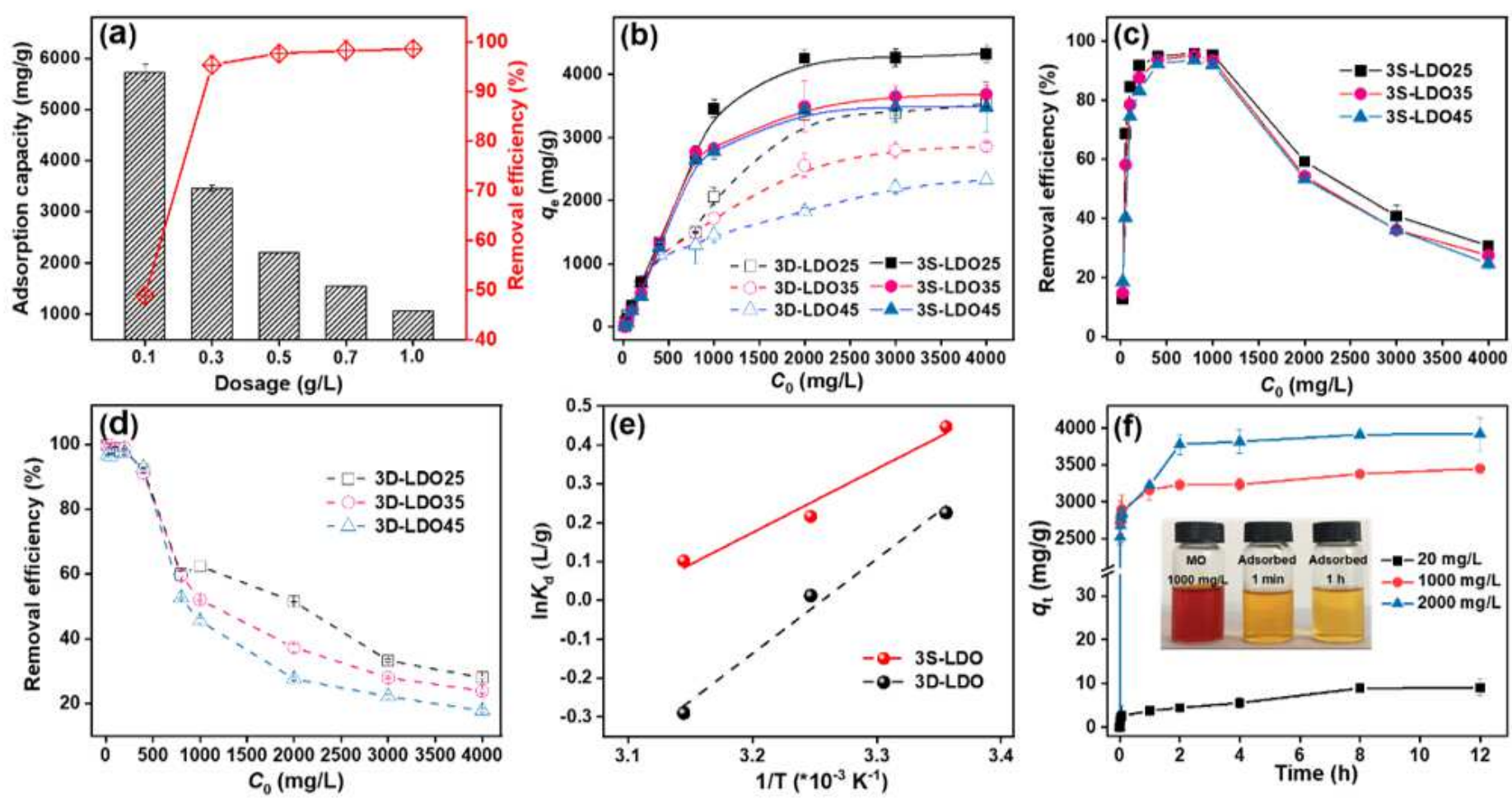

Figure 3

Effect of 3S-LDO dosage on MO adsorption (a); Effect of initial concentration on adsorption of MO by 3SLDO and 3D-LDO at 25, 35, and $45 \otimes(\mathrm{b})$; MO removal efficiency by 3S-LDO (c) and 3D-LDO (d) with increasing initial concentration; Adsorption thermodynamic of MO on 3S-LDO and 3D-LDO (e); Effect of contact time on the $\mathrm{MO}$ adsorption by 3S-LDO with different initial concentrations ( $\mathrm{f}$ ) and the inset in the Figure showed the photographs of aqueous solutions of $\mathrm{MO}$ before and after adsorption. Above experiments were performed via changing corresponding condition and fixing other conditions. The fixed conditions selected from the following value: dosage of $0.3 \mathrm{~g} / \mathrm{L}$, reaction time of $12 \mathrm{~h}$, solution

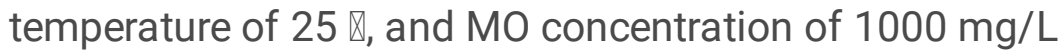





Figure 4

FT-IR spectra (a) and the magnified spectra in a wavenumber range of 400-900 cm-1 (b) of 3S-LDO before and after MO adsorption with various concentrations; High-resolution Mg 1s and Al 2p XPS spectra (c), S $2 p$ XPS spectra (d), N 1s XPS spectra (e) and XRD patterns (f) of 3S-LDO before and after MO adsorption 
(a) EDA interaction

\section{Adsorption 0 .}

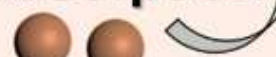

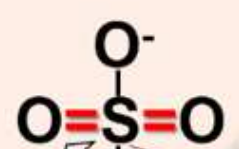
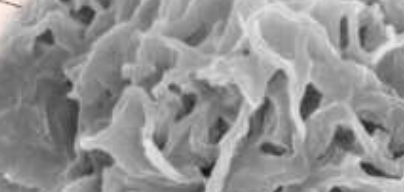

\section{Complexation}
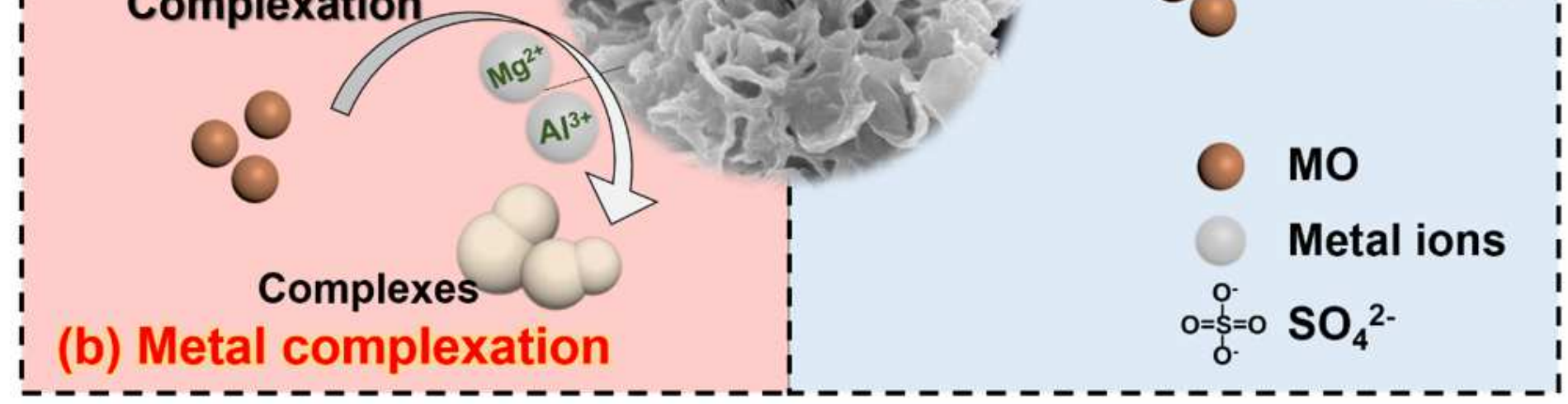

Figure 5

The schematic illustration of 3S-LDO adsorption mechanism for MO


Figure 6

The recyclability of the 3S-LDO for the adsorption of $\mathrm{MO}$ (a). Effects of ionic strength on MO adsorption by $3 S-L D O(b)$. Experiment conditions: $\mathrm{T}=25^{\circ} \mathrm{C}, \mathrm{CO}(\mathrm{MO})=1000 \mathrm{mg} / \mathrm{L}$, adsorbent dosage $=0.3 \mathrm{~g} / \mathrm{L}$, reaction time $=12 \mathrm{~h}$ 
(a)

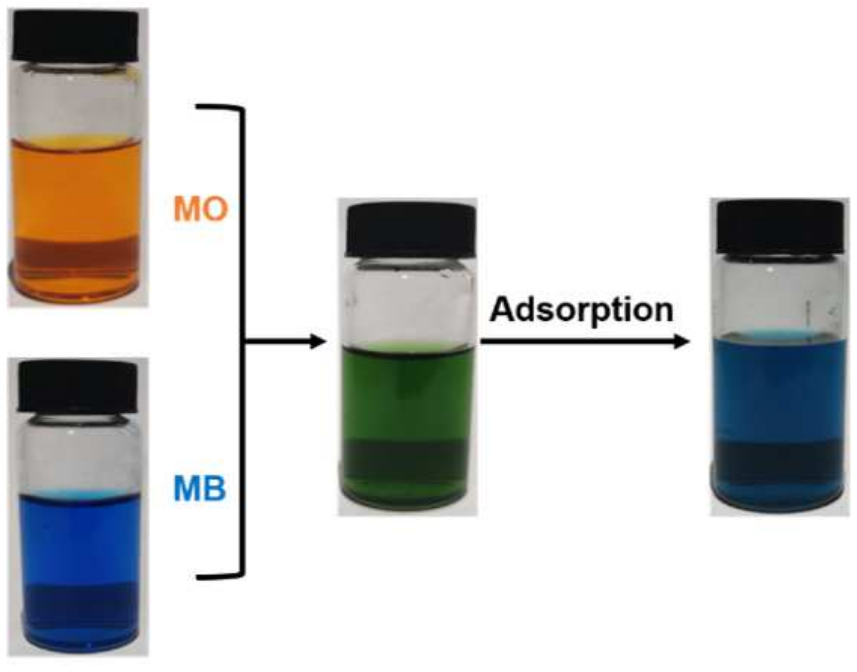

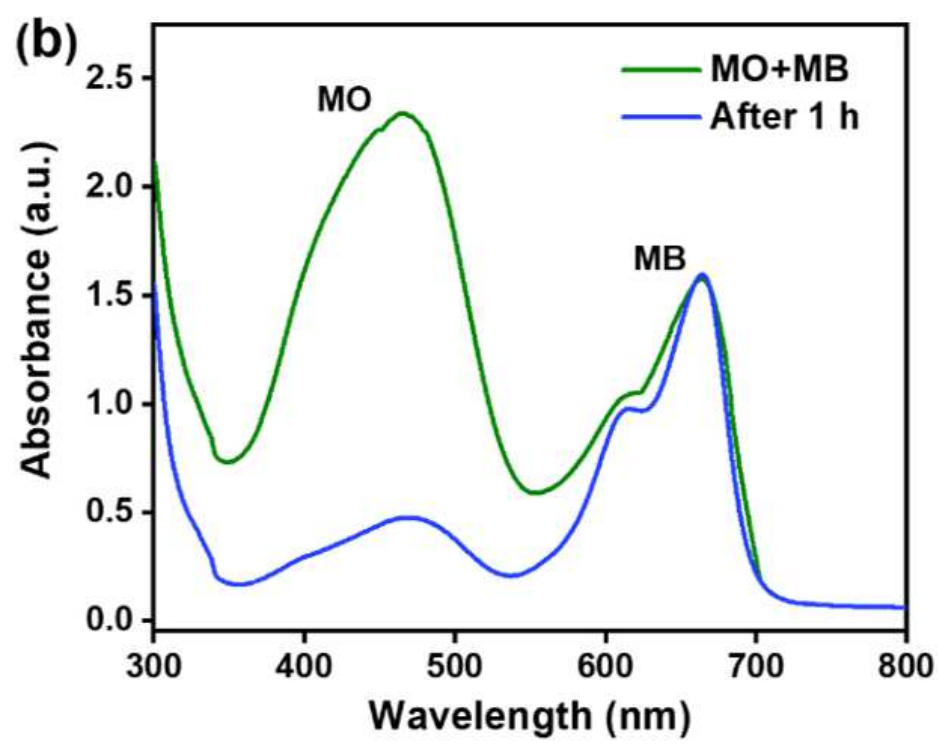

Figure 7

The photos of the selective adsorption $\mathrm{MO}$ from MO/MB mixture solution (a) and the UV-vis spectra of $\mathrm{MO} / \mathrm{MB}$ mixture solution before and after adsorption (b) by 3S-LDO. Experiment conditions: $\mathrm{T}=25^{\circ} \mathrm{C}$, $\mathrm{CO}(\mathrm{MO})=100 \mathrm{mg} / \mathrm{L}, \mathrm{CO}(\mathrm{MB})=50 \mathrm{mg} / \mathrm{L}$, adsorbent dosage $=0.3 \mathrm{~g} / \mathrm{L}$, reaction time $=1 \mathrm{~h}$




Figure 8

$\mathrm{MO}$ removal efficiency of 3S-LDO in real water samples. Experiment conditions: $\mathrm{T}=25^{\circ} \mathrm{C}, \mathrm{CO}(\mathrm{MO})=1000$ $\mathrm{mg} / \mathrm{L}$, adsorbent dosage $=0.3 \mathrm{~g} / \mathrm{L}$, reaction time $=12 \mathrm{~h}$

\section{Supplementary Files}

This is a list of supplementary files associated with this preprint. Click to download.

- SupplementaryMaterial.docx 